\title{
Transsulfuration in an Adult with Hepatic Methionine Adenosyltransferase Deficiency
}

\author{
William A. Gahl,* Isa Bernardini, ${ }^{\star}$ James D. Finkelstein, ${ }^{\star}$ Albert Tangerman, 5 John J. Martin, ${ }^{\ddagger}$ \\ Henk J. Blom," Kevin D. Mullen," and S. Harvey Mudd" \\ *Section on Human Biochemical Genetics, Human Genetics Branch, National Institute of Child Health and Human Development, \\ Bethesda, Maryland 20892; ${ }^{\ddagger}$ Veterans Administration Hospital and George Washington University, Washington, District of Columbia \\ 20422; 'Division of Gastrointestinal and Liver Disease, Department of Medicine, St. Radboud University Hospital, Nijmegen, The \\ Netherlands; "Liver Unit, Digestive Diseases Branch, National Institute of Diabetes and Digestive and Kidney Disease, Bethesda, \\ Maryland 20892;"Laboratory of General and Comparative Biochemistry, National Institute of Mental Health, Bethesda, Maryland 20892
}

\begin{abstract}
We investigated sulfur and methyl group metabolism in a 31-yr-old man with partial hepatic methionine adenosyltransferase (MAT) deficiency. The patient's cultured fibroblasts and erythrocytes had normal MAT activity. Hepatic S-adenosylmethionine (SAM) was slightly decreased. This clinically normal individual lives with a 20-30-fold elevation of plasma methionine (0.72 $\mathrm{mM})$. He excretes in his urine methionine and L-methionine- $d$-sulfoxide $(2.7 \mathrm{mmol} / \mathrm{d})$, a mixed disulfide of methanethiol and a thiol bound to an unidentified group $\mathrm{X}$, which we abbreviate $\mathrm{CH}_{3} \mathrm{~S}-\mathrm{SX}(2.1 \mathrm{mmol} / \mathrm{d})$, and smaller quantities of 4-methylthio-2-oxobutyrate and 3-methylthiopropionate. His breath contains 17-fold normal concentrations of dimethylsulfide. He converts only 6-7 mmol/d of methionine sulfur to inorganic sulfate. This abnormally low rate is due not to a decreased flux through the primarily defective enzyme, MAT, since SAM is produced at an essentially normal rate of $18 \mathrm{mmol} / \mathrm{d}$, but rather to a rate of homocysteine methylation which is abnormally high in the face of the very elevated methionine concentrations demonstrated in this patient. These findings support the view that SAM (which is marginally low in this patient) is an important regulator that helps to determine the partitioning of homocysteine between degradation via cystathionine and conservation by reformation of methionine. In addition, these studies demonstrate that the methionine transamination pathway operates in the presence of an elevated body load of that amino acid in human beings, but is not sufficient to maintain methionine levels in a normal range.
\end{abstract}

\section{Introduction}

We investigated the sulfur and labile methyl group balances of a 31-yr-old man with a severe, yet incomplete, deficiency in the activity of hepatic methionine adenosyltransferase (MAT) ${ }^{1}$ (1). MAT catalyzes the conversion of methionine to S-adenosylmethionine (SAM) (Fig. 1). SAM is a precursor of spermidine and spermine, and the obligatory methyl donor in numerous methyl transfer reactions, forming creatine, phosphatidyl-

Address correspondence and reprint requests to Dr. Gahl, Building 10, Room 10N-318, National Institutes of Health, Bethesda, MD 20892.

Received for publication 21 May 1987 and in revised form 1 September 1987.

1. Abbreviations used in this paper: MAT, methionine adenosyltransferase; SAM, S-adenosylmethionine.

The Journal of Clinical Investigation, Inc.

Volume 81, February 1988, 390-397 choline, methylated derivatives of DNA, RNA, proteins, and catechol amines, carnitine and other compounds (2). In each of these methyl transfers, SAM gives rise to S-adenosylhomocysteine, which is then converted to homocysteine. These are necessary steps in the transsulfuration pathway responsible for most methionine degradation (3). SAM has also been shown by in vitro studies to inhibit the rate of formation of $\mathrm{N}^{5}$-methyltetrahydrofolate by methylenetetrahydrofolate reductase $(4$, 5 ), to stimulate the activity of cystathionine $\beta$-synthase (6), and to inactivate betaine-homocysteine methyltransferase (7). Each of these effects, a priori, endows SAM with the potential to function as an important regulator such that, when SAM is raised, the partitioning of homocysteine would be less toward conservation by methylation to methionine, and more toward conversion to cystathionine for eventual degradation to inorganic sulfate. Although the possibility that the pathway is regulated by the partitioning of homocysteine between these reactions $(8)$ has been studied in intact humans $(2,9,10)$, in isolated rat hepatocytes $(11,12)$, and in model systems reconstituted from cell-free preparations from rats $(13,14)$, and the topic has been reviewed by various authors $(15-17)$, definitive evidence on the in vivo regulatory role of SAM is not available.

In our patient we have now investigated MAT activity in nonhepatic tissues. Such activity may be normal in subjects with decreased hepatic MAT activity (18). We also identified the compound responsible for the patient's unusual breath odor, as well as several sulfur-containing compounds, in addition to methionine, which were present in abnormally elevated amounts in his urine and tissues. Further, we carried out studies that allowed us to estimate the fluxes of sulfur and of labile methyl groups in this patient. These studies furnish strong new evidence that regulatory effects of SAM, previously demonstrated in vitro only, do indeed help determine the extent to which homocysteine is conserved by the human body. Finally, the findings reported here also provide for the first time quantitative insight into the contribution to methionine degradation provided by transamination to 4-methylthio-2-oxobutyrate (19) under conditions of elevated methionine.

\section{Methods}

\section{The patient}

This 31 -yr-old man with $\sim 7 \%$ of normal hepatic MAT activity has been described elsewhere (1). Ascertained by the unusual odor to his breath, he had plasma methionine levels of $0.7 \mathrm{mM}$ ( 25 times normal) with $0.46 \mathrm{mM}$ methionine sulfoxide (see below). Daily urinary excretion of methionine was between 282 and $658 \mu \mathrm{mol}$, and steady-state excretion of methionine sulfoxide was between 1,721 and 2,017 


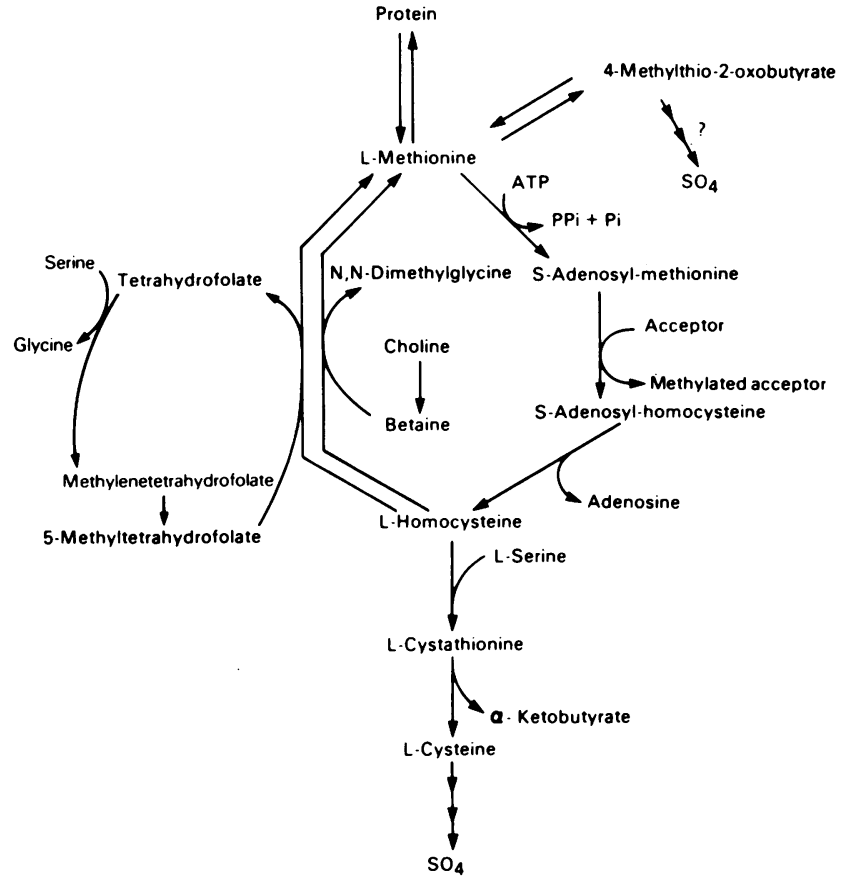

Figure 1. Methionine metabolism and related reactions.

$\mu \mathrm{mol} / \mathrm{d}$, both abnormally elevated. The liver parenchyma contained $25.9 \mathrm{nmol}$ of soluble methionine and methionine sulfoxide/mg of protein. This amounts to $5.5 \mathrm{mmol}$ of methionine $/ \mathrm{kg}$ wet weight, or 16-80 times normal values (1). The hepatic SAM level was slightly decreased, $18 \mu \mathrm{mol} / \mathrm{kg}$ wet weight, compared to published normal values of $35-70 \mu \mathrm{mol} / \mathrm{kg}$ (9). The patient had normal physical and mental development, and liver histology was normal.

\section{Materials}

Polyethylene glycol PEG-6000 was from Koch Chemicals (Colnbrook, Bucks., UK), and from Sigma Chemical Co. (St. Louis, MO), which also supplied indoxyl sulfate, $N$-acetyl-L-methionine, methionine sulfoxide, and 4-methylthio-2-oxobutyrate. Dimethylsulfide was from Merck \& Co. (Darmstadt, Federal Republic of Germany). Bio-Rad Laboratories (Richmond, CA) supplied the resin AG 50W-8X, 100-200 mesh, and Pierce Chemical Co. (Rockford, IL) supplied sulfosalicylic acid. All reagents were of analytical grade.

\section{Methods}

Clinical studies. Clinical investigations were performed after written, informed consent was obtained from the patient. During the sulfur balance studies, the patient received a constant diet, ${ }^{2}$ the methionine and cystine content of which was estimated by the use of published tables $(20,21)$. His body weight remained essentially unchanged during these studies. 24-h urine collections were started and ended at 8 a.m. Urine specimens were refrigerated immediately after passage and pooled and frozen upon completion of each 24-h collection. Blood samples for determination of amino acids were drawn in the morning with the patient in the fasted state. L-Methionine was made up in gelatin capsules containing $250 \mathrm{mg}$ of the amino acid and administered four capsules at a time, once in the morning and once in the evening.

Cell culture. Normal skin fibroblasts (GM-3349A) and lung fibroblasts (IMR-90) from the Human Mutant Cell Repository (Camden, $\mathrm{NJ}$ ), and skin fibroblasts from the patient were grown to confluence in Eagle's minimum essential medium containing $10 \%$ fetal bovine serum (Gibco, Grand Island, NY), and harvested by trypsinization.

2. The food composition of each meal of this daily diet is available upon request.
Enzyme assays. MAT was assayed as described (22). For MAT measurement in erythrocytes, red blood cells were mixed with 2 vol of distilled water and centrifuged at $2,500 \mathrm{~g}$ for $10 \mathrm{~min}$. For fibroblasts, cells were washed twice and suspended in $2 \mathrm{ml}$ of $0.1 \mathrm{M}$ potassium phosphate, pH 7.5, sonicated, and centrifuged. Supernatant fluids were assayed for MAT activity using a 120-min incubation period. One unit of enzyme activity formed $1 \mathrm{nmol}$ of SAM in $60 \mathrm{~min}$. Protein was determined by the Bio-Rad protein assay.

Analyses of amino acids, creatinine, creatine, and carnitine. Amino acids were quantitated using an LKB 4150 alpha amino acid analyzer (LKB Biochrom, Ltd., Cambridge, UK). Urine and heparinized plasma were deproteinized with $5 \%$ sulfosalicylic acid, filtered through $0.22 \mu \mathrm{m}$ Millipore membranes (Millipore Corp., Bedford, MA), and stored at $-20^{\circ} \mathrm{C}$ prior to analysis.

"Bound" methionine was taken as the total of methionine plus methionine sulfoxide in a sample of urine which had been subjected to acid hydrolysis (23), minus the methionine plus methionine sulfoxide present in the same urine without acid hydrolysis (23). This quantity represents methionine liberated from ninhydrin-negative forms (e.g., $\mathrm{N}$-acetylmethionine) without being confounded by any reduction of methionine sulfoxide to methionine which may occur during the acid treatment (24).

Creatinine plus creatine were assayed according to the Jaffe reaction after treatment of urine with hot acid (25). Carnitine was measured as described (26).

Periodate treatment. A sample of urine $(5 \mathrm{ml})$ was titrated to $\mathrm{pH}$ 6.85 with $1 \mathrm{~N} \mathrm{KOH}$. To a $0.45-\mathrm{ml}$ aliquot at $0^{\circ} \mathrm{C}$ was added $0.75 \mathrm{ml}$ of $\mathrm{NaIO}_{4}, 0.25 \mathrm{M}$. After $3 \mathrm{~min}$ at $0^{\circ} \mathrm{C}$, the reaction was stopped by addition of $0.65 \mathrm{ml}$ of ethylene glycol, $2.5 \mathrm{M}$, and an aliquot was used for amino acid analysis. To a second aliquot of the pH 6.85 sample, authentic L-serine and L-threonine $(2 \mu \mathrm{mol}$ each in a total of $0.088 \mathrm{ml}$ $\mathrm{H}_{2} \mathrm{O}$ ) were added prior to treatment with periodate.

2-Mercaptoethanol treatment. A sample of urine $(5 \mathrm{ml})$ was titrated to $\mathrm{pH} 7.5$ with $1 \mathrm{~N} \mathrm{KOH}$. To a $0.5-\mathrm{ml}$ aliquot was added $0.5 \mathrm{ml}$ of a 1:10 (vol/vol) aqueous dilution of 2-mercaptoethanol. The solution was heated in a screw-cap tube at $100^{\circ}$ for $60 \mathrm{~min}$. To a second aliquot of the pH 7.5 sample, authentic L-methionine sulfone $(550 \mathrm{nmol}$ in $0.055 \mathrm{ml}$ of $\mathrm{H}_{2} \mathrm{O}$ ) was added before treatment with 2-mercaptoethanol.

Synthesis and partial resolution of methionine sulfoxides. L-Methionine was treated with $\mathrm{H}_{2} \mathrm{O}_{2}$ in acetic acid as described by Iselin (27). Under these conditions the oxidation has been reported to proceed with some enantio-specificity, producing a preponderance of the L- $d$ diastereoisomer (28). The crude sulfoxide product was further resolved by use of the picrate salts (29) to yield preparations consisting approximately of either $90 \% \mathrm{~L}-d$-, and $10 \% \mathrm{~L}-\mathrm{l}$-methionine sulfoxide or $10 \%$ $\mathrm{L}-d$-, and $90 \% \mathrm{~L}-\mathrm{l}$-methionine sulfoxide.

Sulfur and sulfate determinations. Urinary inorganic sulfate and sulfate esters were measured by the turbidometric method of Lundquist et al. (30), with minor modifications to increase recovery in the case of the sulfate esters. Instead of applying the urine to a column following the removal of inorganic sulfate with $\mathrm{BaCl}_{2}$, the sulfate-free urine $(3 \mathrm{ml})$ was batch-adsorbed in glass tubes with a $1.5-\mathrm{ml}$ packed volume of $A G 50 \mathrm{~W}-\times 8$ ion exchange resin. After vortex-mixing twice, the liquid phase was removed and combined with two distilled water washings $(3 \mathrm{ml})$ of the resin slurry. The combined volume $(8 \mathrm{ml})$ was hydrolyzed by boiling in a $100^{\circ} \mathrm{C}$ water bath for $1 \mathrm{~h}$, and the sulfate content, representing hydrolyzed sulfate esters, was assayed as for free inorganic sulfate. Indoxyl sulfate, $0-6 \mu \mathrm{mol}$, treated as above, provided a standard curve for the assay. Total urinary sulfur was measured by oxidation using Benedict's solution (31) and measuring inorganic sulfate, as above.

Breath analysis. Measured volumes of breath $(100$ and $250 \mathrm{ml})$ were collected in Tenax tubes and sulfur-containing compounds were analyzed by gas chromatography as previously described $(32,33)$.

4-Methylthio-2-oxobutyrate assay. Urinary 4-methylthio-2-oxobutyrate was measured directly by the gas chromatographic method of Favier and Caillat (34). 
Analysis and identification of $\mathrm{CH}_{3} \mathrm{~S}-\mathrm{SX}$. The compound abbreviated $\mathrm{CH}_{3} \mathrm{~S}-\mathrm{SX}$ is the mixed disulfide of methanethiol and a thiol bound to an unidentified group $X$. It was originally identified only as a "base-labile methylthio" compound, and was measured by conversion to methanethiol. To $10 \mu \mathrm{l}$ of urine in a closed evacuated $15-\mathrm{ml}$ glass vial was added $100 \mu \mathrm{l}$ of dithiothreitol $(10 \mathrm{mg} / \mathrm{ml})$ in $0.1 \mathrm{M} \mathrm{Tris}-\mathrm{HCl}$, $\mathrm{pH}$ 10.0. After vortexing for $10 \mathrm{~s}$, the mixture was left at room temperature for $90 \mathrm{~min}$ and $10 \mu \mathrm{l}$ of $10 \mathrm{M}$ acetic acid was injected to release the methanethiol into the headspace. The methanethiol was sampled quantitatively and assayed as for serum (33), yielding the concentration of the base-labile methylthio compound.

4-Methylthio-2-oxobutyrate was also measured indirectly by conversion to methanethiol. After the above procedure was performed for measurement of $\mathrm{CH}_{3} \mathrm{~S}-\mathrm{SX}$, the remaining mixture was flushed with nitrogen to remove traces of free methanethiol, and left at room temperature for $10 \mathrm{~min}$ in the opened vial. The vial was again evacuated and $10-15 \mu \mathrm{l}$ of $10 \mathrm{M} \mathrm{NaOH}$ was injected, bringing the $\mathrm{pH}$ to 12.5-13.0. After vortexing for $15 \mathrm{~s}$ and letting stand for $4 \mathrm{~min}, 30 \mu \mathrm{l}$ of $10 \mathrm{M}$ acetic acid was injected and the released methanethiol was assayed (33). The values for 4-methylthio-2-oxobutyrate obtained by this indirect method corresponded to those obtained by the direct method. 4-Methylthio-2-oxobutyrate appeared stable for at least $4 \mathrm{~d}$ at $4^{\circ} \mathrm{C}$ in urine, whether tested by the direct or indirect method of analysis. This finding contrasts with that of Martensson (35), who reported a marked decrease after $6 \mathrm{~h}$ at room temperature or $4^{\circ} \mathrm{C}$.

The "base-labile methylthio" compound was identified as a mixed disulfide, $\mathrm{CH}_{3} \mathrm{~S}-\mathrm{SX}$, by virtue of the production of appropriate amounts of $\mathrm{CH}_{3} \mathrm{~S}-\mathrm{SCH}_{2} \mathrm{CH}_{3}$ upon addition of a basic solution of ethanethiol to the patient's urine (thiol-disulfide exchange). The chemical identity of the group, " $\mathrm{X}$," is under investigation (Tangerman, A., and H. J. Blom, manuscript in preparation).

3-Methylthiopropionate. This compound was synthesized as described by Kaji et al. (36), and measured in the urine by gas chromatography (36).

\section{Results}

Nonhepatic MAT activity. Extracts of the patient's erythrocytes and fibroblasts each displayed a normal MAT activity (Table I).

Identification of the methionine oxidation product. During chromatography of the patient's urine, an unknown ninhydrin-reactive compound appeared in the area near which serine and threonine elute (Fig. $2 a$ ). Both methionine sulfone and the two diastereoisomers of L-methionine sulfoxide (L-methionine- $l$-sulfoxide and L-methionine- $d$-sulfoxide), elute close to this area, although the sulfoxides resolve from one another. The compound proved insensitive to periodate treatment (Fig. $2 b$ ) and, therefore, is neither threonine nor serine (Fig. 2, $c$ and $d$ ). The unknown was sensitive to 2-mercap-

Table I. MAT Activity in Erythrocytes and Cultured Fibroblasts from a Patient with Hepatic MAT Deficiency

\begin{tabular}{lll}
\hline & \multicolumn{2}{l}{ Methionine adenosyltransferase activity } \\
\cline { 2 - 3 } & Erythrocytes & Fibroblasts \\
\hline units/ml & units/mg protein \\
Normal controls & $5.2,4.0$ & $0.51,1.25$ \\
Patient & 4.4 & 0.81 \\
\hline
\end{tabular}

Results are means of multiple determinations: erythrocytes (3), fibroblasts (4). Erythrocyte controls were from two men aged 31 and 36 yrs. Fibroblast controls were from a human skin biopsy (first value) and from human fetal lung cells (second value).
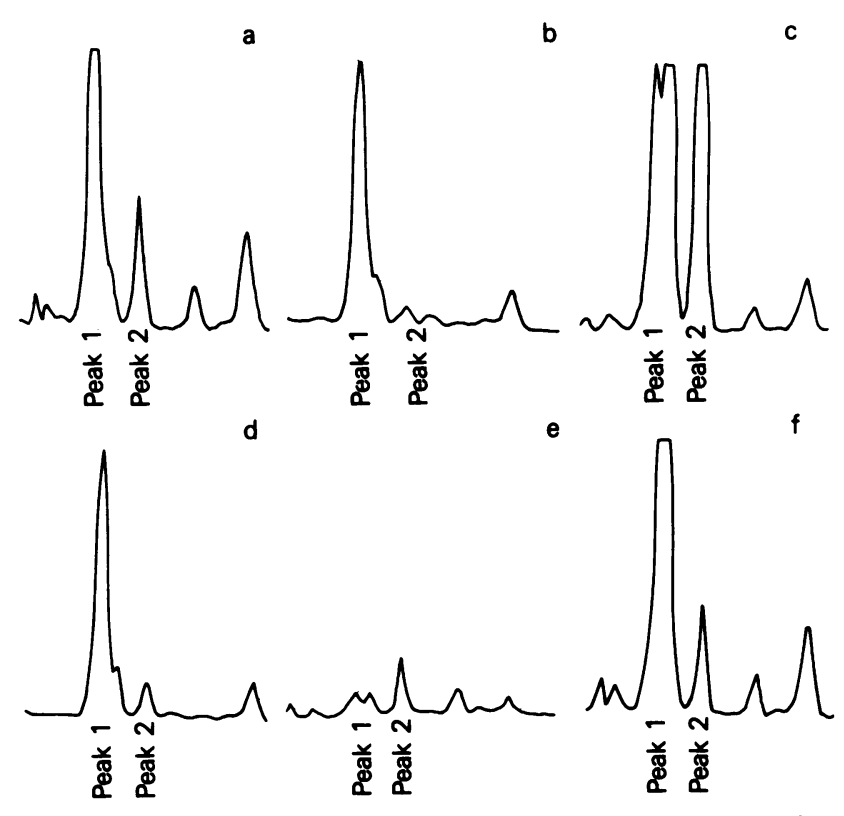

g
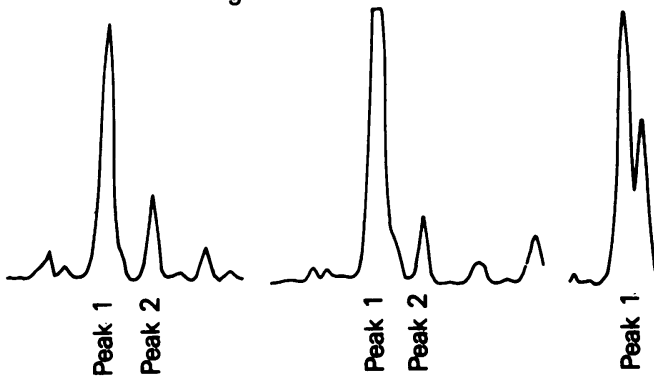

i

Figure 2. Determination of chemical structure of methionine oxidation product in the urine of MAT-deficient patient. (a) Portion of amino acidogram of patient's untreated urine $(40 \mu \mathrm{l})$. Peak 1 contains unknown compound and threonine. Peak 2 represents serine. (b) After periodate treatment. Threonine is gone from peak 1; serine from peak 2. (c) Same as $a$, but with added serine and threonine. $(d)$ Same as $c$, after periodate treatment. (e) Same as $a$, after 2-mercaptoethanol treatment. Peak 1, containing unknown compound, is diminished. $(f)$ Same as $a$, but with added methionine sulfone, which elutes with peak 1. (g) Same as $f$, after 2-mercaptoethanol treatment. Methionine sulfone is relatively insensitive to 2-mercaptoethanol. (h) Same as $a$, but with added L-methionine- $d$-sulfoxide. Note single peak. ( $i$ ) Same as $a$, but with added L-methionine-l-sulfoxide. Two peaks indicate that unknown compound is not the $L-l$-diastereoisomer.

toethanol (Fig. $2 e$ ), suggesting it is a methionine sulfoxide rather than methionine sulfone (Fig. $2, f$ and $g$ ). Finally, the unknown coeluted with authentic L-methionine- $d$-sulfoxide (Fig. $2 h$ ), but separated from L-methionine-l-sulfoxide (Fig. 2 $i)$. These results identified the urinary methionine oxidation product as L-methionine- $d$-sulfoxide.

Chromatography of the patient's plasma yielded an amino acid profile in the area of interest identical to that for his urine. Therefore, the likely origin of the urinary L-methionine- $d$-sulfoxide was the patient's plasma.

Sulfur balance studies in steady state. The patient, weighing $73 \mathrm{~kg}$, selected a palatable diet, normal for him, and adhered to the same menu for $7 \mathrm{~d}$. The diet was free of meat and, therefore, essentially devoid of creatine and creatinine and 
very low in $N$-methylhistidines (37) and carnitine (38). It contained 3,014 calories, $87.7 \mathrm{~g}$ of protein, $11.2 \mathrm{mmol}$ methionine, $9.3 \mathrm{mg}$-atom cystine sulfur, and $3.6 \mathrm{mmol}$ choline. During the final $2 \mathrm{~d}$ of the diet, the patient collected his urine, which was analyzed for various sulfur-containing compounds (Table II). Sulfur intake ( $20.5 \mathrm{mg}$-atom) was roughly balanced by urinary excretion ( $22.1 \mathrm{mg}$-atom). Of the total urinary sulfur, $65 \%$ was in the form of sulfate. Free methionine $(0.5$ mmol), "bound" methionine $(0.5 \mathrm{mmol})$, and methionine sulfoxide ( $1.7 \mathrm{mmol}$ ) accounted for $12 \%$ of total sulfur excretion.

Sulfur balance studies during methionine restriction and supplementation. The patient was placed for $11 \mathrm{~d}$ on a diet with methionine lowered to $4.8 \mathrm{mmol} / \mathrm{d}$. Cystine was close to normal at $6.8 \mathrm{mg}$-atom sulfur/d, and the choline content was approximately $3.6 \mathrm{mmol} / \mathrm{d}$. For the last $5 \mathrm{~d}$ of this regimen, a supplement of L-methionine (13.4 mmol) brought the methionine intake to $18.2 \mathrm{mmol}$. Total urinary sulfate did not reflect the changes in methionine intake, falling only slightly during methionine restriction, from 14.0 to $10.4 \mathrm{mmol} / \mathrm{d}$ and barely returning to $13.6 \mathrm{mmol} / \mathrm{d}$ with methionine supplementation. Plasma methionine and methionine sulfoxide concentrations did not fall substantially under methionine restriction, but did increase marginally during supplementation (Fig. 3). Changes in urinary methionine and methionine sulfoxide mirrored somewhat the changes in plasma levels, starting at $1.8 \mathrm{mmol} /$

Table II. Urinary Excretion of Sulfur-containing Compounds by MAT-deficient Patient in Steady-State Sulfur Balance

\begin{tabular}{|c|c|c|}
\hline \multirow[t]{2}{*}{ Compound } & \multicolumn{2}{|c|}{ Daily urinary excretion } \\
\hline & mg-atom of $S$ & $\%$ of total $S$ \\
\hline a. Total sulfur & 22.1 & 100 \\
\hline$b$. Inorganic sulfate & 12.9 & 58 \\
\hline c. Esterified sulfate & 1.5 & 7 \\
\hline d. Total sulfate $(b+c)$ & 14.4 & 65 \\
\hline e. Calculated organic sulfur $(a-d)$ & 7.7 & 35 \\
\hline f. Methionine + methionine sulfoxide & 2.2 & 10 \\
\hline g. Bound methionine* & 0.5 & 2 \\
\hline h. 4-Methylthio-2-oxobutyrate ${ }^{\ddagger}$ & 0.1 & 0 \\
\hline i. 3-Methylthiopropionate & 0.03 & 0 \\
\hline j. $\quad \mathrm{CH}_{3} \mathrm{~S}-\mathrm{SX}$ & 4.2 & 19 \\
\hline k. Dimethylsulfide & 0.00 & 0 \\
\hline l. Taurine + cystine & 1.6 & 7 \\
\hline \multicolumn{3}{|l|}{ m. Identified organic sulfur $(f+g$} \\
\hline$+h+i+j+k+l)$ & 8.6 & 39 \\
\hline
\end{tabular}

The patient received a fixed normal diet containing $11.2 \mathrm{mmol}$ of methionine and $9.3 \mathrm{mg}$-atom of cystine sulfur daily for $7 \mathrm{~d}$. Values listed are for a 24-h urine collected on day 6 of the regimen. On this day, creatinine excretion was $14.3 \mathrm{mmol}$. A second 24-h urine collected on day 7 contained similar amounts of each sulfur compound if corrected for the creatinine recovery, which was $72 \%$ of that on day 6 , and outside the range of creatinine excretions for collections made in the hospital (see Results). Note similarity between calculated and identified organic sulfur.

* Corrected for $85 \%$ recovery determined for acetylmethionine after extensive acid hydrolysis.

‡ The degradation product, 4-methylthio-2-hydroxybutyrate (35), was not measured but is expected to be small, i.e., $<0.1 \mathrm{mg}$-atom of $\mathrm{S}$.

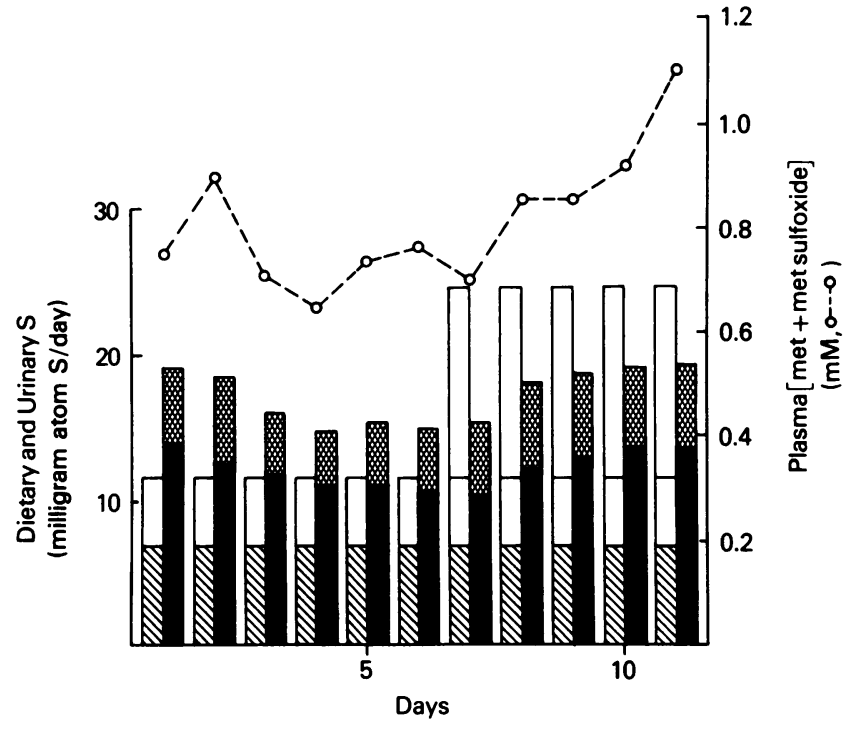

Figure 3. Urinary excretion of total sulfur and sulfate before and after the administration of supplemental L-methionine. Each day is represented by two bars. The left-hand bar represents dietary cystine (hatched rectangle) plus methionine (open rectangle). The right-hand bar represents urinary excretion of total sulfate (solid bar) and of nonsulfate sulfur (cross-hatched bar). The patient received a fixed diet throughout the study. Starting on day 7 , the diet was supplemented with oral L-methionine (1 gram b.i.d.; total $13.4 \mathrm{mmol}$ ) in capsule form. Plasma methionine plus methionine sulfoxide concentration is plotted for each day of the study.

$\mathrm{d}$, falling to $1.0 \mathrm{mmol} / \mathrm{d}$ on days 6 and 7 , and returning to 1.9 mmol/d by day 11 (data not shown). These compounds never contributed $>10 \%$ of the total sulfur excretion. Total urinary sulfur, $19.1 \mathrm{mg}$-atom on the first day, fell only to $15.1 \mathrm{mg}$ atom during the period of methionine restriction, and reached only $19.4 \mathrm{mg}$-atom during methionine supplementation. As a result, during the $6 \mathrm{~d}$ of methionine restriction the patient had a net negative sulfur balance of $27.8 \mathrm{mg}$-atom, whereas during the $5 \mathrm{~d}$ of methionine supplementation he had a net positive balance of $37.4 \mathrm{mg}$-atom.

Production of creatinine and other methylated metabolites. Because decreased availability of SAM might limit creatine synthesis and, consequently, creatinine production, we determined whether the MAT-deficient patient produced a normal amount of creatinine. Several facts suggested that he did. His muscle mass appeared grossly normal. He participated in rigorous long-distance running. His total body potassium (140.1 g), determined in a whole-body counting chamber, revealed a lean body mass of $63.8 \mathrm{~kg}$, or $87 \%$ of total body weight $(73 \mathrm{~kg})$. Standards indicate that this should be reflected by a total daily creatinine production of $14.7 \mathrm{mmol}$ (39). In fact, four 24-h urine collections contained $13.9 \pm 0.4 \mathrm{mmol}$ creatinine. During the steady-state balance studies, urinary creatinine + creatine excretion amounted to $14.3 \mathrm{mmol} / \mathrm{d}$ (Table III); urinary total carnitine, $0.2 \mathrm{mmol} / \mathrm{d}$; and methylhistidines, $0.4 \mathrm{mmol} / \mathrm{d}$.

Identification of volatile sulfur compounds. The patient's breath, analyzed by gas chromatography, revealed a dimethylsulfide concentration of $5.86 \pm 0.11 \mathrm{nM}$ (mean $\pm \mathrm{SD}, n=5$ ). Normal values $(n=20)$ are $0.34 \pm 0.03 \mathrm{nM}$ (range, $0.13-0.65$ nM) (33). No methanethiol or dimethyldisulfide was detected in the breath. 
Table III. Steady-State SAM Formation, Methyl Balance, and Methylneogenesis in a MAT-deficient Patient

Compound Methyl moieties

meq/24h

a. Urinary creatinine + creatine

14.3

b. Urinary carnitine

0.2

c. Urinary 3-methylhistidine +1 -methylhistidine

0.4

d. Other methylated compounds in urine*

0.8

e. Sarcosine from SAM ${ }^{\ddagger}$

2.2

$f$. Spermidine and spermine

0.5

g. Total SAM formation $(a+b+c+d+e+f)$

18.4

$h$. Methyls used for methylations $(g-f)^{\S}$

17.9

$i$. Urinary methionine (free + bound)

+ methionine sulfoxide

j. Urinary 4-methylthio-2-oxobutyrate

0.03

Urinary 3-methylthiopropionate

2.1

$m$. Respiratory dimethylsulfide

0.1

n. Total methyl utilization and loss $(h+i+j$ $+k+l+m)$

o. Dietary methionine

q. Total dietary labile methyls $(o+p)$

8.8

See legend to Table II.

* Estimated from reference 2, Table 3, with adjustments.

₹ Estimated from reference 8 .

Estimated from reference 2, Table 4. No net consumption of labile methyls results from the reactions forming spermidine and spermine. The methyls in question are recycled to methionine through methylthioadenosine and methylthioribose (50).

Duplicate blood concentrations of dimethylsulfide were 73 and $96 \mathrm{nM}$ (normal 3-6 nM [33]). No other volatile sulfur compounds were identified. Dimethylsulfide in the patient's urine, collected under conditions which did not ensure against losses due to volatility, was $400 \mathrm{nM}$ (normal, $2 \mathrm{nM}$ ). Normal small amounts of methanethiol were also identified in the urine.

Methionine transamination metabolites in urine. For eight 24-h urines collected under different dietary regimens, the patient's mean $\pm \mathrm{SD}$ excretion of 4-methylthio-2-oxobutyrate was $5.6 \pm 2.4 \mathrm{mmol} / \mathrm{mol}$ creatinine (normal $0.047 \pm 0.015, n=10$ [Blom, H. J., et al., manuscript in preparation]). During steady state, the patient's daily output of 4-methylthio-2-oxobutyrate amounted to $0.1 \mathrm{mmol}$ (Table II, $h$ ).

The patient's excretion of 3-methylthiopropionate under steady-state conditions was $2.0 \mathrm{mmol} / \mathrm{mol}$ creatinine (normal, $0.022 \pm 0.024, n=10$ [Blom, H. J., et al., manuscript in preparation]), amounting to $0.03 \mathrm{mmol} / \mathrm{day}$ (Table II, $i$ ).

The "base-labile methylthio" compound, $\mathrm{CH}_{3} \mathrm{~S}-\mathrm{SX}$, was present in six $24-\mathrm{h}$ collections at $166 \pm 14 \mathrm{mmol} / \mathrm{mol}$ creatinine (normal, 1.7 $\pm 0.7, n=10$ [Blom, H. J., et al., manuscript in preparation]). During methionine restriction (days 6 and 7, Fig. 3), the patient's value was $66 \mathrm{mmol} / \mathrm{mol}$ creatinine. The total amount of $\mathrm{CH}_{3} \mathrm{~S}-\mathrm{SX}$ excreted during steady state was 2.1 $\mathrm{mmol} / \mathrm{d}$ (Table II, $j$ ).

\section{Discussion}

Our patient with hepatic MAT deficiency has been normal mentally and physically for at least three decades (1). Presumably, this reflects the presence of some residual MAT activity in his liver (1) and the normal MAT activity in his nonhepatic tissues (Table I). The latter finding is similar to that reported for other patients with hepatic MAT deficiency $(18,40)$, and is consistent with the occurrence of forms of MAT in extrahepatic tissues under genetic control separate from that of the high $K_{\mathrm{m}}$ hepatic form.

A variety of sulfur-containing compounds are excreted by this patient in elevated quantities:

(a) Methionine and methionine sulfoxide, now identified as the L-methionine- $d$-sulfoxide diastereoisomer (Fig. 2). At a plasma concentration of $460 \mu \mathrm{M}$ the latter accounted for $\sim 1.7 \mathrm{mg}$-atom of the daily urinary sulfur excretion. The presence of only one diastereoisomer suggests that the compound is formed enzymatically by a reaction not previously described in human beings.

(b) Compounds derived via the methionine transamination pathway:

1. 4-Methylthio-2-oxobutyrate, the immediate product of methionine transamination (41). Direct assay of urine gave a value of $0.1 \mathrm{mmol} / \mathrm{d}$ under steady-state conditions. This compound has been similarly increased in other patients with hypermethioninemia (34), and in normal subjects after ingestion of D-, but not L-methionine (42). The latter finding may be attributed to the fact that to enter the mainstream of methionine metabolism the D-isomer, unlike the L-, must undergo either oxidation by D-amino acid oxidase or transamination.

2. 3-Methylthiopropionate, the urinary excretion of which amounted to $0.03 \mathrm{mmol} / \mathrm{d}$. In rat tissues, this compound is formed by oxidative decarboxylation of 4-methylthio-2-oxobutyrate (43). It is increased also in normal humans after administration of D-methionine (36).

3. Dimethylsulfide, the only volatile sulfur-containing compound increased in the breath of our patient, and accounting for the unusual breath odor which was his presenting complaint. With a minute volume of expiration of 8 liters, the patient's 17-fold normal level of expired dimethylsulfide (5.9 $\mathrm{nM}$ ) would result in a net loss of 0.14 mequivalent of methyl groups and $0.07 \mathrm{mg}$-atom of sulfur/d. The urinary excretion of dimethylsulfide was small. Dimethylsulfide increases in breath of normal humans after administration of D-, but not L-methionine (44). It may derive its sulfur atom and one methyl group from 4-methylthio-2-oxobutyrate, since methanethiol is a degradation product of 3-methylthiopropionate in rats (45). The second methyl group would then come via a transmethylation reaction involving SAM; an hepatic enzyme that performs this methylation has recently been described (46).

4. The mixed disulfide, $\mathrm{CH}_{3} \mathrm{~S}$-SX, quantitatively important, with a urinary excretion of $2.1 \mathrm{mmol} / \mathrm{d}$. To our knowledge this compound has not been found before in humans or other mammals. Although the identity of the -SX portion of the molecule remains to be established, preliminary findings indicate this moiety derives, directly or indirectly, from cysteine (Tangerman, A., and H. J. Blom, manuscript in preparation). The $\mathrm{CH}_{3} \mathrm{~S}$ - moiety appears to derive from 4-methylthio2-oxobutyrate, or a metabolite thereof (45). 
Total identified urinary sulfur in these organic compounds and in taurine and cystine (excreted in normal quantities by our patient) was $8.6 \mathrm{mmol}$ (Table II, $m$ ). This value agreed well with the total urinary organic sulfur calculated as the difference between total sulfur and total sulfate (Table II, $e$ ). Thus the quantitatively important organic sulfur-containing compounds in the patient's urine have been identified, although minor amounts of others may be present. For example, the action of lactate dehydrogenase would be expected to form an amount of 4-methylthio-2-hydroxybutyrate roughly commensurate with the amount of 4-methylthio-2-oxobutyrate (35). The hydroxy compound was not measured directly in the present experiments.

The patient's excretion of sulfur-containing and methylcontaining compounds was measured while he was on several constant dietary intakes. These determinations (Tables II and III, and Fig. 3) were used to estimate the fluxes of sulfur and of labile methyl groups in the presence of a severe deficiency of hepatic MAT (Tables III and IV). Several unexpected and important points emerge from these tables:

(a) The patient forms at least $14.9 \mathrm{mmol} / \mathrm{d}$ of SAM (Table III, sum of the measured quantities of the methylated excretory products creatinine, creatine, carnitine, and $N$-methylhisti-

Table IV. Sulfur Fluxes in MAT-deficient Patient in Steady-State Sulfur Balance

\begin{tabular}{ll}
\hline Compound & Sulfur \\
\hline
\end{tabular}

$m g$-atom $/ 24 h$

a. Dietary cystine

b. Urinary cystine and taurine

9.3

Urinary $\mathrm{CH}_{3} \mathrm{~S}-\mathrm{SX}^{*}$

d. Sulfate from cystine $(a-b-c)$

e. Dietary methionine

f. Urinary free and bound methionine and methionine sulfoxide, 2.7; 4-methylthio-2oxobutyrate and dimethylsulfide, $0.1 ; \mathrm{CH}_{3} \mathrm{~S}$ SX, 2.1

g. Respiratory dimethylsulfide

$h$. Sulfate from methionine $(e-f-g)$

$i$. Homocysteine from transmethylation reactions

$j$. Homocysteine recycled $(i-h)$

$k$. Adjusted dietary choline

l. Minimum homocysteine recycled by $\mathrm{N}^{5}$ methyltetrahydrofolate $(j-k)^{\ddagger}$

4.9

0.1

6.2

17.9

11.7

8.8

See legend to Table II.

* The -SX portion of this disulfide is presumed to derive from cysteine (Tangerman, A., and H. J. Blom, manuscript in preparation). If it derived from methionine instead, the value of $l$ would be even greater, i.e., 10.9 .

$\ddagger$ In making this calculation it is assumed that methyl moieties equivalent to the "adjusted dietary choline" are used for betaine-dependent methylation of homocysteine. This is consistent with evidence from intact humans even under conditions in which SAM is presumably not decreased (9). Thus, normally, there may well be sufficient betaine-homocysteine methyltransferase activity to utilize all available betaine, and any possible increase in the activity of this enzyme due to lower than normal SAM concentrations (7) has not been invoked. dines). To this can almost surely be added another $3.5 \mathrm{mmol}$ estimated by indirect means (Table III, $d+e+f$ ), giving a total of $18.4 \mathrm{mmol} / \mathrm{d}$. Thus, in spite of his proven defect in hepatic MAT, the patient is forming an amount of the product of this enzyme which is normal for young adult males on normal diets $(2,9)$. This normal flux is presumably achieved by the buildup of methionine (to $720 \mu \mathrm{M}$ ) which permits any residual activity of the high $K_{\mathrm{m}}$ hepatic form of MAT to function closer to its maximal velocity than is the case at a normal methionine concentration. In normal humans the hepatic methionine concentration is well below half-saturation for the high $K_{\mathrm{m}}$ form of MAT (apparent $K_{\mathrm{m}}, 650 \mu \mathrm{M}$ ), the form that provides $91 \%$ of the maximal adult capacity to form SAM (47). Flux through the low $K_{\mathrm{m}}$ form(s) of MAT may also be increased at the patient's increased methionine concentration, although current uncertainties as to the kinetic constants of these isoenzymes in humans prevent accurate estimation of the magnitude of this effect.

(b) In spite of the fact that a normal amount of methionine passes through the primary block at MAT, the patient converts an abnormally low proportion of methionine sulfur to sulfate. In steady state with a normal daily methionine intake of 11.2 $\mathrm{mmol}$, he spilled $4.9 \mathrm{mmol}$ of methionine, methionine sulfoxide, 4-methylthio-2-oxobutyrate, 3-methylthiopropionate, dimethylsulfide, and $\mathrm{CH}_{3} \mathrm{~S}$-SX into the urine, leaving only 6.2 mmol of methionine sulfur to be converted to sulfate (Table IV, $h$ ). His total urinary sulfate contributed only $65 \%$ of the total urinary sulfur (normal, $80.1 \pm 5.3 \%$ ). In addition, when given an abnormally high intake of methionine, the patient failed to convert the added sulfur virtually quantitatively to sulfate, as a normal subject would. In $5 \mathrm{~d}$ of methionine supplementation (Fig. 3), urinary sulfate increased by a total of $10.5 \mathrm{mmol}$ while methionine intake increased by $68.5 \mathrm{mmol}$; thus only $15 \%$ of added methionine sulfur was converted to sulfate. Contributing to this lack of response by the patient is the damping effect of his large body load of methionine. Given a plasma volume of 3.5 liters with $720 \mu \mathrm{M}$ methionine, this compartment would contain $2.5 \mathrm{mmol}$ of methionine. A 1,200 -g liver with $5.5 \mathrm{mmol}$ of methionine $/ \mathrm{kg}$ wet weight would contain $6.6 \mathrm{mmol}$. If plasma and liver have methionine concentrations representative of extracellular fluid (18.3 liters) and intracellular fluid (25.6 liters), respectively, the patient's total body methionine would approximate $154 \mathrm{mmol}$. Therefore, variations in methionine intake would only slightly perturb the concentration of this amino acid in his bodily fluids.

The patient does convert the bulk of his cyst(e)ine sulfur to sulfate. Of $9.3 \mathrm{mg}$-atom cystine sulfur taken in, $1.6 \mathrm{mg}$-atom are excreted as taurine plus cystine (Table IV, $b$ ). The only abnormal excretory compound in this patient which may derive (in part) from cysteine is the mixed disulfide, $\mathrm{CH}_{3} \mathrm{~S}$-SX. If the -SX portion of this compound is formed from cysteine (Tangerman, A., and H. J. Blom, manuscript in preparation), the $2.1 \mathrm{mg}$-atom of sulfur excreted daily during steady-state balance in the -SX portion of $\mathrm{CH}_{3} \mathrm{~S}-\mathrm{SX}$ (Table IV, $c$ ) should be subtracted from the cysteine sulfur available for conversion to sulfate. Daily formation of sulfate from cysteine would then be $5.6 \mathrm{mg}$-atom plus the amount of cysteine formed from methionine.

(c) In spite of his high body-load of methionine, the patient conserves a sizable amount of this amino acid by $\mathrm{N}^{5}$-methyltetrahydrofolate-dependent methylation of homocysteine. Of 
the $18.4 \mathrm{mmol}$ of SAM formed daily, virtually all (17.9 $\mathrm{mmol})$ is utilized in transmethylation reactions (Table III, $h$ ). Thus $17.9 \mathrm{mmol}$ of homocysteine must arise from S-adenosylhomocysteine. Approximately $6.2 \mathrm{mmol}$ of this homocysteine is metabolized to sulfate (Table IV, $h$ ), leaving 11.7 to be methylated back to methionine (Table IV, $j$ ). Betaine arising from dietary choline contributes at most 2.9 meq of the methyl groups needed for this recycling of homocysteine, leaving the remainder to be donated by $\mathrm{N}^{5}$-methyltetrahydrofolate. Thus, methyl groups are being formed by neogenesis at a rate of at least $8.8 \mathrm{mmol} / \mathrm{d}$ (Table IV, $l$ ). The same value is obtained if one calculates the methylneogenesis as the amount by which methyl utilization and loss exceed the total dietary intake of labile methyls (Table III, $r$ ). Whereas this rate of homocysteine recycling due to new formation of methyls might be regarded as normal, or high normal, for a normal young adult male on a normal methionine intake with a normal methionine body load (2), it is excessively high for the same subject ingesting excess methionine (9). A normal person would dispose of the excess methionine by increasing his rate of SAM formation, using the SAM to methylate glycine to sarcosine, and oxidizing the methyl group of sarcosine; meanwhile the increased homocysteine formed from SAM would be metabolized quickly and quantitatively to sulfate with minimal recycling of homocysteine to methionine (9). This sequence avoids the conservation of methionine in the presence of excess methionine which is a striking feature of our patient. Three mechanisms may contribute to our patient's abnormal methionine conservation. First, since his MAT is probably operating near saturation with respect to methionine, any further increment in methionine may only marginally increase the flux through MAT to produce added amounts of SAM. Second, although methionine is elevated in this patient, SAM is not. Thus the decrease in the rate of formation of $\mathrm{N}^{5}$-methyltetrahydrofolate by SAM inhibition of methylenetetrahydrofolate reductase (4), expected to occur in a normal subject when methionine concentrations are increased, does not occur in this patient, and he continues to have ample amounts of $\mathrm{N}^{5}$-methyltetrahydrofolate available for homocysteine methylation. Third, the expected stimulation of cystathionine $\beta$-synthase activity by increased SAM (6), which may normally divert a greater portion of available homocysteine toward cystathionine, would not take place in this patient. The latter two effects achieve continued methionine conservation in the face of extreme methionine (but not SAM) excess. ${ }^{3}$

(d) Finally, the present studies help define the role in humans of the methionine transamination pathway described by Benevenga and colleagues $(19,41,43)$. The contribution of this pathway to methionine catabolism in our patient may be taken as the sum of the amounts of 4-methylthio-2-oxobutyrate and its metabolic products, 3-methylthiopropionate, dimethylsulfide, and the $\mathrm{CH}_{3} \mathrm{~S}$-moiety of $\mathrm{CH}_{3} \mathrm{~S}-\mathrm{SX}$. Since this

3. In this interpretation, it is implied that the concentration of SAM is not so low as to produce a functionally significant decrease in the activity of $\mathrm{N}^{5}$-methyltetrahydrofolate-homocysteine methyltransferase. The latter enzyme depends for its activity upon SAM $(48,49)$. Billings et al. (12) have reported evidence, however, suggesting this enzyme attains maximal activity at a concentration of SAM somewhat below that in normal liver, whereas a higher than normal concentration of SAM is required to inhibit methylenetetrahydrofolate reductase. approximates $2.3 \mathrm{mg}$-atom sulfur/d (Table II), the net amount of methionine undergoing conversion to 4-methylthio-2-oxobutyrate is at least $20 \%(2.3 / 11.2 \times 100 \%)$ of the dietary intake. ${ }^{4}$ This rate is attained under conditions of abnormal methionine accumulation due to the primary block at MAT. The transamination pathway is clearly inadequate to prevent this accumulation. ${ }^{5}$

We note that our conclusions may not pertain in their entirety to patients with isolated hypermethioninemia due to abnormalities other than that of hepatic MAT (3), or to patients with a complete MAT deficiency, who may be more seriously affected both chemically and clinically.

\section{Acknowledgments}

We appreciate the excellent dietary consultation and analysis of Pamela Brye, Department of Nutrition, Clinical Center, NIH, and the fine secretarial assistance of Colleen Genovese.

This work was supported in part by the Veterans Administration and by grant AM-13048 to Dr. Finkelstein from the National Institutes of Health.

\section{References}

1. Gahl, W. A., J. D. Finkelstein, K. D. Mullen, I. Bernardini, J. J. Martin, P. Backlund, K. G. Ishak, J. H. Hoofnagle, and S. H. Mudd. 1987. Hepatic methionine adenosyltransferase deficiency in a 31year-old man. Am. J. Hum. Genet. 40:39-49.

2. Mudd, S. H., and J. R. Poole. 1975. Labile methyl balances for normal humans on various dietary regimens. Metab. Clin. Exp. 24:721-735.

3. Mudd, S. H., and H. L. Levy. 1983. Disorders of Transsulfuration. In The Metabolic Basis of Inherited Disease. 5th edition. J. B. Stanbury, J. B. Wyngaarden, D. S. Fredrickson, J. L. Goldstein, and M. S. Brown, editors. McGraw-Hill Book Co., Inc., New York. 522-559.

4. Kutzbach, C., and E. L. R. Stokstad. 1967. Feedback inhibition of methylene-tetrahydrofolate reductase in rat liver by S-adenosyl-methionine. Biochim. Biophys. Acta. 139:217-220.

5. Kutzbach, C., and E. L. R. Stokstad. 1971. Mammalian methylenetetrahydrofolate reductase. Partial purification, properties, and inhibition by S-adenosylmethionine. Biochim. Biophys. Acta. 250:459477.

6. Finkelstein, J. D., W. E. Kyle, J. J. Martin, and A-M. Pick. 1975. Activation of cystathionine synthase by adenosylmethionine and adenosylethionine. Biochem. Biophys. Res. Commun. 66:81-87.

7. Finkelstein, J. D., and J. J. Martin. 1984. Inactivation of be-

4. This is a minimal estimate since a portion of the sulfur originating in 4-methylthio-2-oxobutyrate may ultimately be converted to sulfate, and would not have been taken into account in the calculation used here. However, the amount of sulfate formed by this route is likely to be small, since only $6.2 \mathrm{mmol}$ of sulfate is derived daily from methionine, an amount very small relative to the $\sim 17.9 \mathrm{mmol}$ of homocysteine formed daily, and available for degradation to sulfate by the transsulfuration pathway. We presume, therefore, that most of the sulfate which derives from methionine does so via transsulfuration. 5. The conclusion that the transamination pathway is inadequate to catabolize a normal load of methionine is supported also by the previous demonstration that humans blocked in the transsulfuration pathway due to genetically determined deficient cystathionine-synthase activity are grossly defective in their maximum capacity to convert methionine sulfur to sulfate $(23,31)$. Furthermore, 4-methylthio2-oxobutyrate was assayed in the urine of one such patient. Even in a state of marked hypermethioninemia induced by methionine loading, this patient excreted only $0.16 \mathrm{mmol}$ of the keto acid daily (23). 
taine-homocysteine methyltransferase by adenosylmethionine and adenosylethionine. Biochem. Biophys. Res. Commun. 118:14-19.

8. Finkelstein, J. D., and S. H. Mudd. 1967. Transsulfuration in mammals: the methionine-sparing effect of cystine. J. Biol. Chem. 242:873-880.

9. Mudd, S. H., M. H. Ebert, and C. R. Scriver. 1980. Labile methyl group balances in the human: the role of sarcosine. Metab. Clin. Exp. 29:707-720.

10. Young, V. R., K. Storch, D. Wagner, and J. F. Burke. 1987. The methionine cycle in man: Response to a methionine-free diet with/without cystine. Fed. Proc. 46:572. (Abstr.)

11. Krebs, H. A., R. Hems, and B. Tyler, 1976. The regulation of folate and methionine metabolism. Biochem. J. 158:341-353.

12. Billings, R. E., P. E. Noker, and T. R. Tephly. 1981. The role of methionine in regulating folate-dependent reactions in isolated rat hepatocytes. Arch. Biochem. Biophys. 208:108-120.

13. Finkelstein, J. D., and J. J. Martin. 1984. Methionine metabolism in mammals. Distribution of homocysteine between competing pathways. J. Biol. Chem. 259:9508-9513.

14. Finkelstein, J. D., and J. J. Martin. 1986. Methionine metabolism in mammals. Adaptation to methionine excess. J. Biol. Chem. 261:1582-1587.

15. Finkelstein, J. D. 1978. Regulation of Methionine Metabolism in Mammals. In Transmethylation. E. Usdin, R. T. Borchardt, and C. R. Creveling, editors. Elsevier/North Holland, New York. 49-58.

16. Mudd, S. H. 1980. Diseases of sulphur metabolism: Implications for the methionine-homocysteine cycle, and vitamin responsiveness. In Sulphur in Biology. Ciba Found. Symp. 72:239-258.

17. Cooper, A. J. L. 1983. Biochemistry of sulfur-containing amino acids. Annu. Rev. Biochem. 52:187-222.

18. Gaull, G. E., H. H. Tallan, D. Lonsdale, H. Przyrembel, F. Schaffner, and D. B. Bassewitz. 1981. Hypermethioninemia associated with methionine adenosyltransferase deficiency: clinical, morphologic, and biochemical observations on four patients. J. Pediatr. 98:734-741.

19. Mitchell, A. D., and N. J. Benevenga. 1978. The role of transamination in methionine oxidation in the rat. $J$. Nutr. 108:67-78.

20. Orr, M. L., and B. K. Watt. 1968. Amino acid content of foods. U. S. Department of Agriculture Home Economics Research Report No. 4.

21. U. S. Department of Agriculture, Agriculture Research Service. 1984. Composition of Foods. Agriculture Handbook Nos. 8-12.

22. Mudd, S. H., J. D. Finkelstein, F. Irreverre, and L. Laster. 1965. Transsulfuration in mammals. Microassays and tissue distributions of three enzymes of pathway. J. Biol. Chem. 240:4382-4392.

23. Laster, L., S. H. Mudd, J. D. Finkelstein, and F. Irreverre. 1965. Homocystinuria due to cystathionine synthase deficiency: the metabolism of L-methionine. J. Clin. Invest. 44:1708-1719.

24. Ray, W. J., Jr., and D. E. Koshland, Jr. 1962. Identification of aminoacids in phosphoglucomutase action. J. Biol. Chem. 237:24932505.

25. Jaffe, J. 1886. Ueber der Niederschlag, welchen Pikrinsaure in normalem Harn erzeugt und über eine neue Reaction des Kreatinins. Z. Physiol. Chem. 10:391-400.

26. Bernardini, I., W. B. Rizzo, M. Dalakas, J. Bernar, and W. A. Gahl. 1985. Plasma and muscle free carnitine deficiency due to renal Fanconi syndrome. J. Clin. Invest. 75:1124-1130.

27. Iselin, B. 1961. Derivate von L-methionin-sulfoxyd und ihre Verwendung für Peptidsynthesen. Helv. Chim. Acta. 44:61-78.

28. Berezin, B. B., I. A. Yamskov, and V. A. Davankov. 1983. Ligand-exchange chromatography of amino acid racemates on polystyrene sorbents containing L-methionine- $d$-sulfoxide or L-methionine-l-sulfoxide groups. J. Chromatogr. 261:301-304.

29. Lavine, T. F. 1947. The formation, resolution, and optical properties of the diastereoisomeric sulfoxides derived from methionine. J. Biol. Chem. 169:477-491.

30. Lundquist, P., J. Martensson, B. Sorbo, and S. Ohman. 1980. Turbidometry of inorganic sulfate, ester sulfate and total sulfur in urine. Clin. Chem. 26:1178-1181.
31. Poole, J. R., S. H. Mudd, E. B. Conerly, and W. A. Edwards. 1975. Homocystinuria due to cystathionine synthase deficiency. Studies of nitrogen balance and sulfur excretion. J. Clin. Invest. 55:10331048.

32. Tangerman, A., M. T. Meuwese-Arends, and J. H. M. van Tongeren. 1983. A new sensitive assay for measuring volatile sulphur compounds in human breath by Tenax trapping and gas chromatography and its application in liver cirrhosis. Clin. Chim. Acta. 130:103110.

33. Tangerman, A., M. T. Meuwese-Arends, and J. H. M. van Tongeren. 1985. New methods for the release of volatile sulfur compounds from human serum: its determination by Tenax trapping and gas chromatography and its application in liver diseases. J. Lab. Clin. Med. 106:175-182.

34. Favier, A., and D. Caillat. 1977. Dosage par chromatographie gazeuse avec détection en photométrie de flamme de l'acide alpha-céto-gamma-méthylthiobutyrique urinaire dans les hyperméthioninémies. Clin. Chim. Acta. 79:419-423.

35. Martensson, J. 1986. The occurrence of 4-methylthio-2-hydroxybutyrate in human urine. Anal. Biochem. 154:43-49.

36. Kaji, H., K. Saito, N. Saito, M. Hisamura, M. Ishimoto, and H. Kondo. 1983. Simple gas chromatographic analysis of 3-methylthiopropionate in human urine. J. Chromatogr. 272:166-169.

37. Block, W. D., R. W. Hubbard, and B. F. Steele. 1965. Excretion of histidine and histidine derivatives by human subjects ingesting protein from different sources. J. Nutr. 85:419-425.

38. Borum, P. R. 1983. Carnitine. Annu. Rev. Nutr. 3:233-259.

39. Calloway, D. H., and S. Margen. 1971. Variation in endogenous nitrogen excretion and dietary nitrogen utilization as determinants of human protein requirements. J. Nutr. 101:205-216.

40. Tallan, H. H. 1979. Methionine adenosyltransferase in man: evidence for multiple forms. Biochem. Med. 21:129-140.

41. Benevenga, N. J., and A. R. Egan. 1983. Quantitative Aspects of Methionine Metabolism. In Sulfur Amino Acids: Biochemical and Clinical Aspects. K. Kuriyama, R. J. Huxtable, and H. Iwata, editors. Alan R. Liss, Inc., New York. 327-341.

42. Kaji, H., N. Saito, M. Murao, M. Ishimoto, H. Kondo, S. Gasa, and K. Saito. 1980. Gas chromatographic and gas chromatographicmass spectrophotometric studies on $\alpha$-keto- $\gamma$-methylthiobutyric acid in urine following ingestion of optical isomers of methionine. J. Chromatogr. (Biomed. Appl.). 221:145-148.

43. Steele, R. D., and N. J. Benevenga. 1978. Identification of 3-methyl-thiopropionic acid as an intermediate in mammalian methionine metabolism in vitro. J. Biol. Chem. 253:7844-7850.

44. Kaji, H., M. Hisamura, N. Saito, and M. Murao. 1981. Biochemical aspect of dimethyl sulfide breath test in the studies of methionine metabolism. Res. Commun. Chem. Pathol. Pharmacol. 32:515523.

45. Steele, R. D., and N. J. Benevenga. 1979. The metabolism of 3-methylthiopropionate in rat liver homogenates. J. Biol. Chem. 254:8885-8890.

46. Hoffman, J. L., K. P. McConnell, and N. Mozier. 1987. Sadenosylmethionine-dependent selenium methylation in vivo and in vitro. Fed. Proc. 46:572. (Abstr.)

47. Liau, M. C., C. F. Chang, L. Belanger, and A. Grenier. 1979. Correlation of isozyme patterns of S-adenosylmethionine synthetase with fetal stages and pathological states of liver. Cancer Res. 39:162169.

48. Mangum, J. H., and J. A. North. 1971. Isolation of a cobalamin containing 5-methyltetrahydrofolate-homocysteine transmethylase from mammalian kidney. Biochemistry. 10:3765-3769.

49. Huennekens, F. M., P. M. DiGirolamo, K. Fijii, D. W. Jacobsen, and K. S. Vitols. 1976. $B_{12}$-dependent methionine synthetase as a potential target for cancer chemotherapy. Adv. Enzyme Regul. 14:187-205.

50. Backlund, P. S., Jr., and R. A. Smith. 1981. Methionine synthesis from 5'-methylthioadenosine in rat liver. J. Biol. Chem. 256:15331535 . 